\title{
Hyperactive Kids-Why Does Healing with the Constitutional Remedy Happen?
}

\author{
Sigrid Lindemann ${ }^{1}$ \\ ${ }^{1}$ Tamil Nadu, India \\ Homœopathic Links 2015;28(1):23-26.
}

Address for correspondence Sigrid Lindemann, Svedam, 605101

\begin{abstract}
Auroville, Tamil Nadu, India (e-mail: sigrid@auroville.org.in).
\end{abstract}
Abstract
Keywords
- Hyperactivity
- Sympathetic arousal
- Sensation method
- Cenchris contortrix

Several immediate healing responses in hyperactive kids prompted me to develop the following perspective: The constitutional remedy reestablishes balance between hyperactivity-characterised by sympathetic arousal-and restoration. This perspective allows me for clear evaluation of follow-up after prescribing with the sensation method.

\section{Giving an Impulse toward Homeostasis}

Today more and more children are speedy, unfocused, 'jumping jacks', and get diagnosed with attention deficit/hyperactivity disorder (ADHD). This more often leads to prescription of Ritalin, though extensive literature of successful alternative treatment of ADHD is available.

According to allopathic medicine, the body is a conglomeration of biochemical processes-which will get rectified by chemical substances with psychiatric drugs such as Ritalin.

Alternative medicine sees the body as an energy field, and healing occurs through giving an impulse to self-regulate toward homeostasis.

Healing is achieved by addressing the 'energy field' with information: acupuncture, Ayurveda, fasting, bodywork (Bowen etc.), energy work as well as classic homeopathy.

While practicing the sensation method, and being trained in somatic experiencing (SE), hypnotherapy, and regression work (TASSO), ${ }^{*}$ several drastic healing experiences in patients incited me toward the following perspective.

A well-chosen homeopathic remedy reestablishes a harmonious energy field, by balancing its sympathetic and parasympathetic nervous system. Looking at a case with this perspective gives clarity in prescription and follow-up.

\section{Hyperactive Kids}

Hyperactive kids with behavioural problems often exhibit traits of being in a 'fight-or-flight' mode, as if their sympathetic nervous system is activated:

\footnotetext{
Tasso International offers an international program in Transpersonal Regression Therapy: www.tassointernational.com.
}

- They are visually hyperactive, and therefore can be very easily distracted visually.

- Their hearing is highly acute, and they are therefore easily distracted by sounds.

- They have a big need for movement; being extremely restless.

- They are unable to relax; to take a moment, they are constantly 'on the go'.

Many hyperactive kids have no sense of hunger, nor would they feel satisfied having a full stomach. Many do not feel pain, or opposite they feel it very acutely. In some cases, hyperactive children even try to cause themselves pain 'to finally feel something'.

Most of them have difficulties to calm down and need a long time till they are able to fall asleep. Then, all of a sudden, they are 'fast asleep', in a deep slumber. Very often these children suffer from nasty nightmares-which their parents are usually unaware of.

In school they have difficulties with activities involving the frontal lobe of the brain-reading, writing, calculating, analytical thinking-which adds to their day-to-day difficulties.

\section{Fight-or-Flight Mechanism}

When comparing the so-called behavioural problems of these kids with the 'acting out of the fight-or-flight mechanism as if in a threat for survival', one can but observe striking similarities.

The survival mechanism with an activated sympathetic nervous system overpowers the rational thought processes and the activities of the frontal brain. 
This hierarchy of function of the brain ensures the survival of human beings till today.

It also means being still and calm will lead to death.

In acute survival situations, the visual and auditory senses are extremely sharp, and the extremities are restless-ready for 'fight or flight'. The individual's sensitivity to pain is greatly reduced, so as to protect from what may come.

In this state, it is impossible to 'gently drift into sleep' and there is increased restlessness.

The parasympathetic nervous system, which stimulates appetite, digestion, rest and restoration, is set aside temporarily. The function of the frontal cortex-reading, calculation etc.-is 'not that important' at this point, because the individual is focused on survival.

There seems to be a lack of harmony and flexibility to switch from sympathetic to parasympathetic nervous system, and of moving toward homeostasis.

\section{Homeopathy-Sensation Method}

In case of receiving, we distinguish 'the human song' from the 'nonhuman song'-the song from nature. The homeopathic remedy is identified by discovering the 'nonhuman song' within the human.

'The human song' is characterised through the common themes of mammal life:

- Survival in family and group rather than alone

- A safe place to live, to be at ease

- Being connected with one's family

- A need for communication and learning

- Mastery (or suppression) of instincts (aggression and sexuality) to be part of the group, which in turn is necessary for survival

Specific for the human are as follows:

- Finding a balance between egoism and altruism, between 'being there for oneself' and 'being there for others', sensing social responsibility.

- The desire for personal growth and self-realisation.

\section{The Other Song-from Nature}

These are the specific survival mechanisms, which evolved within each species in nature, reflected in our homeopathic remedies.

In animals, survival is obvious in victim-aggressor themes; in plants, we find survival mechanisms in sensitivity to specific environmental stimuli, and survival in minerals is about function, form and completeness of its structure.

The professional homeopathic approach with specific case-taking techniques combined with the systematic analysis with the Sankaran method ${ }^{1}$ produces highly reliable results in prescribing a homeopathic simillimum. This constitutional 'healing agent from nature' will restore healthy balance in patients for many years.

\section{Case Taking}

In children, the focus on case taking is to directly approach 'the other song', through the child's spontaneous and intense characteristics. This works particularly well with children of ages 4 to 10, as they express their vital energy in their activities without any compensation or need for self-control. Topics in case taking are the natural affinities of the child, such as movement patterns, games, sports and hobbiesfurthermore, their fears, dreams, favourite movies and video games as well as 'when I am big' fantasies, which give insight into the so-called specific magical world of a child. This information, combined with physical symptoms and general characteristics, determines a highly individualised remedy.

Problems within family, school and social environment mainly reflect the difficulties with the 'human life'. The child is not able to adapt his individual behaviour to match the expectations of the community and society. Details of these difficulties are unspecific and mostly secondary for the individualisation and choice of the remedy. At times the child does not even see his inability to adapt as problem, and is therefore not interested in change, and, more often though, adaption and flexibility are out of reach for the child.

\section{The Homeopathic Simillimum}

The simillimum integrates the 'human song' with the 'nonhuman song', and gives an impulse for a harmonious interaction of sympathetic and parasympathetic nervous system:

- Phases of activity and quietness and concentration interlude.

- Appetite and hunger appear, and eating becomes a satisfying experience.

- The child now feels himself and how tired he is-falling asleep is easy.

- The body is sensed more acutely, and pain is noticedsometimes for the first time in their life.

- Some children get physically sick after a very long time. Finally their life force lets the body-mind systems work together in a dynamic way. Having a cold with fever is an update of the immune system.

- And...

- The frontal brain, whose function had been overrun by the 'fight-or-flight' mechanism, is coming to the forefront again.

- Reading, writing and calculating come easily, and homework is done in 20 minutes and becomes a positive experience-compared with the 2-day frustration and fight with their parents before.

- The child is now able to sit still in class, and is less distracted by sounds and visuals.

In general, these changes develop gradually over several weeks, but nightmares disappear faster. It is usually very noticeable that the child gains gradually more control over his instinctive reactions. 


\section{Why Does the Sympathetic Nervous System or the Fight-or-Flight Mechanism Gets Activated?}

- Trauma at a young age

- Being left alone, neglect in early childhood

- Violence in the family

- Lack of appropriate care (according to age)

- Birth trauma (lack of oxygen, caesarean, use of forceps, etc.)

- Prenatal trauma (medication, nicotine, alcohol consumption by the mother, or violence)

- Effects of vaccination, for example silent encephalitis

- Major accidents, operations

- An overload of sensory input-as created by too much TV, mobile use, video games, etc.

A very large input of information, at any time, creates an overload for the rational mind, which in turn activates the survival mechanism.

The good news is that a constitutional remedy can give an impulse toward homeostasis. The remedy seems to be able to restore the flexibility between sympathetic and parasympathetic functioning. Utmost precision in the choice of the remedy and its potency are a prerequisite to this deep work.

\section{Short Case}

I was alerted to the earlier perspective by several dramatic successes with hyperactive children. Since then this view has added clarity in prescription and follow-up.

A. is a boy of 7 years, very skinny and nervous, and wears very strong glasses. He has always been a weirdo for most children and adults. He walks through life without observing and connecting to anything and anybody. He rarely finds somebody to play with, and rather plays hours at the computer. He is very jealous of his 4-year-old sister, who goes through life with ease. When he joins primary school, it is obvious after 2 weeks that he cannot fit in-even though it's a kind of Steiner (Rudolf Steiner, founder of Anthroposophy) school. His mother couldn't find a kindergarten that could integrate him earlier already.

He is raised by his Mum only, and his father doesn't care since years and lives abroad. His father is an artist and an alcoholic. The relationship was marked by abuse and violence.

His mother mentioned that A. tells about his bloody nightmares every morning at breakfast. In the consultation with me he talks in bits, moving his hands wildly while describing:

'A cave where somebody became a monster, he got teeth like hooks, a lot of blood'. 'A ghost falls in love with a girl, he grabs her by the throat, takes her to a door opened by a skeleton. The ghost then poisons the girl, and enters its body, the girl is dead-but alive'. Another story: 'A boy abuses a girl by touching the breasts. A magician with hooked teeth orders a monster to bite the hands of the boy, and then cuts up the boy in thousand pieces'. 'A clown master: he is twins in reality: one is lovely, one is bad'. 'A girl loves her father, but she is a monster girl. She is like an enormous earthworm and eats up the father. Thereafter the father rips off the heads of infants'.

In the session with his mother, she mentioned that he is never ill. He is very afraid of the dark and takes long to fall asleep. He is afraid of dogs. He always quarrels with his sister. He is solitary, unpredictable and does not seem to feel empathy or emotions. He has a strong desire for bacon.

\section{Case Analysis with Rubrics}

- Dreams of cutting bodies, dead infants, sexual dreams, rape, snakes, teeth

- Dreams appear true on waking

- Desire for bacon

- These point to Cenchris contortrix (-Fig. 1).

The systematic analysis substantiates the vital sensation, not only in his dreams but his overall behaviour:

Animal remedy: aggressor and victim.

Reptile group: solitary, unfeeling, two sides-a lovely and a bad side, jealousy, aggression with poison leading to bleeding.

\section{Follow-up}

After 10 days Cenchris C30 daily, the next day he stopped reporting his dreams. Now he rarely dreams like this. His behaviour shifted drastically. He can play 2 hours with new kids-unlike earlier when his mother had to intervene every 10 minutes because he was unfair or jealous with others. Now his mother can train him in reading and writing for 20 minutes, which was impossible earlier. He quarrels much less with his sister and nags his mother much less; life is easier for everybody.

Now, $1 \frac{1}{2}$ years later he is well integrated in school, best student in math, reads and writes fluently and has many friends. He is happy and dares to dance in front of people in the schoolyard. Scary dreams come up very rarely. Only scenes in the dark with unknown fear once a month, but

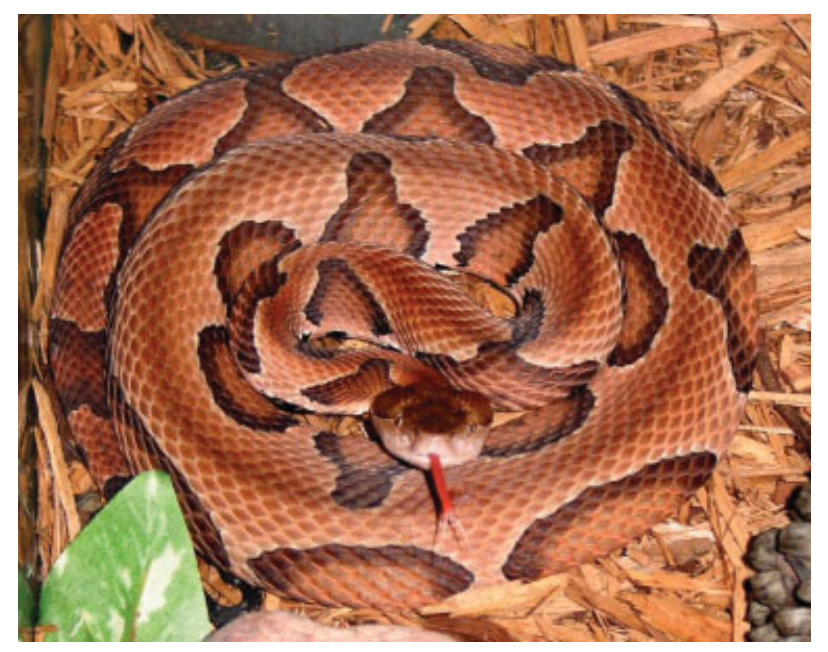

Fig. 1 Cenchris contortrix (http://ilovehomoeopathy.com). 
no more bloody scenes. When this happens, it is time to repeat the remedy and in 2013 he received Cenchris C200 four times.

\section{Conclusion}

His nightmares-the song of the snake-were so active that he constantly lived in 'fight-or-flight' alert. With the remedy the nonhuman element, the human song (song of nature) is being balanced and the patient can grow into his human potential.

\section{Observations}

If kids are stressed, overstimulated, 'on fight-or-flight', get restless and fail to reestablish a healthy balance, what about adults?

Is there any difference-basically not? Basically it's the same. It's the stress, our individual stress, too much of strain that leads to disease. 'Stress' can be an overly functioning on the sympathetic arousal, and too little bouncing back and forth between restoration and action.

Peter Chappell and Harry van der Zee's book Homeopathy for Diseases ${ }^{2}$ contains several chapters on trauma and its release due to the healing impulse of PC trauma remedies (war trauma, rape trauma, incest trauma, shock trauma, etc.). The chapters on theory and treatment of trauma depict a similar perspective to the one quoted earlier. Although classic homeopathy uses an individualised approach, PC remedies were developed such that they can be used by trained laypersons. Therefore, PC trauma remedies can reach many in need in a most efficient way, as demonstrated in the book in their many case studies.

Peter Levine's Waking the Tiger ${ }^{3}$ goes into detail of releasing pent-up trauma and freeze in 'somatic experiencing therapy'. I have seen impressive results of this 'simple technique', reestablishing a healthy balancing mechanism between sympathetic arousal and restoration.

\section{Vita}

Sigrid Lindemann has been practicing the sensation method since 2000 in Auroville, an intentional community in South India. She is member of WISH, and has been teaching with English and German video cases since 2004 in Germany and Spain.

She works with a very international clientele and researches homeopathy in the context of regression therapy, somatic experiencing and other approaches.

www.sigridlindemann.de

\section{References}

1 Sankaran R. The Other Song. Mumbai, India: Homoeopathic Medical Publishers; 2008

2 van der Zee H, Chappell P. Homeopathy for Diseases. Haren, The Netherlands: Homeolinks Publishers; 2012

3 Levine P. Waking the Tiger: Healing Trauma. Berkeley, CA: North Atlantic Books; 1997

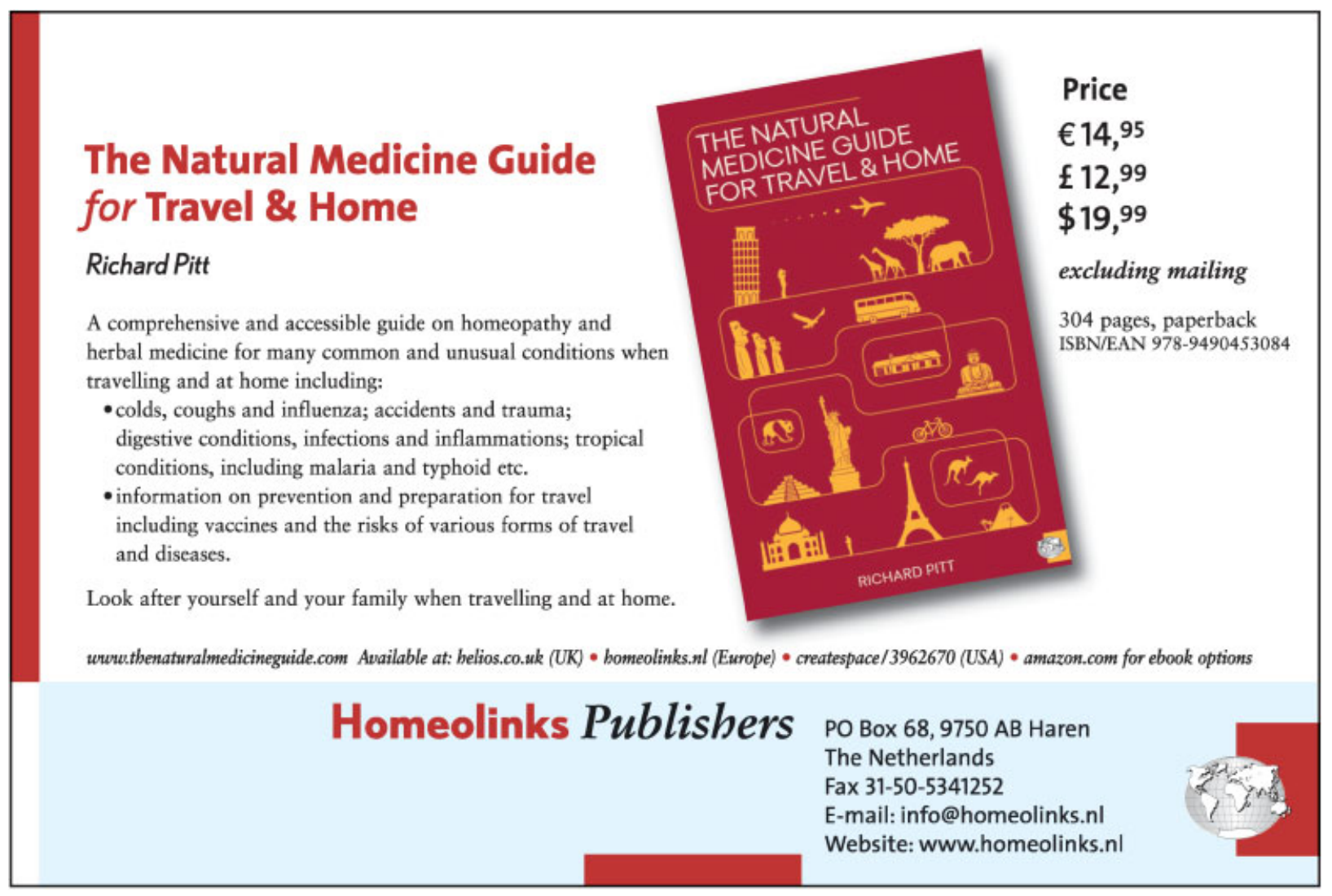

